\title{
Structural-Syntactic Features of Undetached Appositions in Modern English Azerbaijani State University of Economy
}

\author{
Muradova Nargiz Nazim ${ }^{1}$ \\ ${ }^{1}$ Azerbaijan State University of Economy, Baku, Azerbaijan \\ Correspondence: Muradova Nargiz Nazim, Azerbaijan State University of Economy, Baku, Azerbaijan. E-mail: \\ s.gurbanova@yahoo.com
}

Received: March 20, 2015

Accepted: April 15, 2015 Online Published: May 30, 2015

doi:10.5539/ijel.v5n3p165

URL: http://dx.doi.org/10.5539/ijel.v5n3p165

\begin{abstract}
The article embraces the study of structural syntactic features of undetached appositions in Modern English. The main aim of the investigation is to study role and place of oppositions in the English linguistics. The thoughts of the scholars in the study of oppositions, the determination of oppositions as to their types and functions, terms related to the oppositions are differently used by scholars. Having mentioned all these varieties in the determination of appositions, we have offered the terms undetached and detached oppositions, instead of other terms offered by other scholars. In the scope of the study consideration of the problem among the Azerbaijani-English studying scholars has taken place as well. Investigations show that there is not a unanimous determination of oppositions and usage of terminology related to the oppositions.
\end{abstract}

Keywords: detached, non-detached, coordination, subordination, conjunction

\section{Introduction}

There is no unanimous thought on the apposition and its essence as a syntactic category in the modern English linguistics. Particularly on two problems the ideas of the scholars seriously differ:

1) on the place of apposition among the sentence members; 2) on the determination of the types of appositions in the English language.

The information, given by V.A.Ilyish in the theroetical course, called "The Structure of the Modern English Language" as to its essence, basically differs from the thoughts of other scholars. He comes to the conclusion that apposition must be studied not as another type of attribute, but as an another separately-taken secondary sentence member (Ilyish, 1971) Considering this thought we may come to the conclusion that in the modern English language the number of sentence members is not five, but it must be six. It is worth mentioning that, there is no one to share this opinion of professor V.A.Ilyish. In the known to us languages apposition is introduced as a type of attribute. We think that there is no need to artificially increase the number of sentence members.

Speaking on the essence of apposition, we think it also necessary to touch upon the apposition, which is much spoken of lately, alongside the thought grounded on the specifying sentence member. In the Russian linguistics, including the investigations carried out lately, alongside the apposition, specifying sentence member is also spoken about.

The thought, that the specifying sentence member can refer both to the main and secondary sentence members, is taken as a basis. The specifying members carrying out the same syntactic functions with the sentence members, which they belong to accents the meaning of a specified word, at a certain degree in a compact form. The existing difference between the apposition and the specifying sentence is indicated as follows. Apposition is expressed only by a noun, whereas specifying sentence members can be expressed by word combinations, expressed by different parts of speech and by different types of subordinate clauses (Van Yuy Fu, 1956). We think this mentioned thought can belong to the modern English language as well. At least, as to the fact that during the last days, in the investigations carried out on the materials of the English language, including the classic English grammar books, we come across such an opinion that apposition belonging to all the sentence members, can be expressed by the separately-taken words, word combinations and by subordinate clauses. 
We'd also like to mention the condition, for if we accept the category of specifying sentence members, then we may come to the conclusion that we can imagine sentence members in this category in any language as well: main sentence members, secondary sentence members, specifying sentence members and apposition. Undoubtedly, if we approach the solution of the problem in this form, we might have made some errors in the study and teaching sentence members.

We'd like to note that some scholars basing upon concrete language facts come to such a conclusion that, no difference between the apposition and specifying sentence member, from the formal or form, the functional view point shows itself (Sviblova, 1962).

Basing upon this view point, also investigated language facts, we, in our investigation of the problem, base upon the opinion that in any language, the language units called as specifying sentence member are nothing more than different variants of apposition in the language. Here we can speak of only full and partial types of appositions.

One of the disputable problems is associated with the problem of number of apposition. Traditionally in the modern English language two types of apposition is indicated: close apposition, loose apposition. But in some investigations only one type of apposition is accepted. Maria Dolores and Gomez Penas sharing the view point of Burton-Roberts come to the conclusion that in the modern English language there is only one type of apposition - loose apposition. They base upon the idea that in the combinations of close apposition type (Doctor Brown) the first component bears the features of an attribute (Dolores \& Gomez, 1994) This mentioned thought doesn't reflect the reality correctly because in such type of combinations the first component can't bear the feature of attribute in any way for such combinations as we shall point out further on, are formulated not on the ground of subordination but on the ground of coordination (appositive link). Just for this reason in our investigation we rely on the thought that appositions possess two types: a) undetached appositions; b) detached appositions.

\section{Research Methodology}

In this article comparative typological analysis of theoretical approach to the problem, problem of dichotomy of language-speech, also study of semantic structural and functional problems of undetached oppositions have been used.

\section{Scope of the Study}

Before considering the essence of the problem we'd better show our attitude to some terms used on appositions.

Traditionally in English linguistics terms such as "close" and "loose" related to appositions are used: a) close apposition; b) loose apposition.

At the same time some of the linguists use the terms "restrictive" and "non-restrictive" (Quirk, 1982)

Another group of linguists take advantage of using "detached" and "non-detached" terms related to appositions (Khaimovitch \& Rogovskaya, 1967)

The equivalents of these terms in the Azerbaijanian English study first have been used as "close" (asili) and "loose" (sərbəst) appositions by the author of the book "English Grammar" R.Gayibova (Gayibova, 1956).

But prof. O.Musayev as to their essence divides the appositions into 2 groups: close (qeyri-sərbəst) and loose (sərbəst) (Musayev, 2007).

We, approaching the problem from the view of general linguistics, think it necessary to consider the appositions as undetached and detached. That's the reason why we use the terms undetached and detached related to appositions.

In the undetached appositions as an apposition noun is used. The very word being used in the function of attribute characterizes it from different aspects.

\section{Structural-Syntactic Features of Undetached Oppositions}

Different from detached apposition undetached appositions together with the word which they belong to are pronounced within one sense group, there does not exist any pause between them. The words which are used as appositions express the meanings such as trade, profession, title, rank, relationship and so on: Professor Brown, Doctor Imanov, etc.

Now let's consider concrete language facts.

1. We will send her to Aunt Clara's (To Let, 156).

2. This sailor-fellow has been the only man she was in touch with (L.London, 170). 
3. In that old war, of course, his nephew Val Dartie had been wounded (To Let, 20).

4. I am going to help Mother Smith with the cookies she's prepared for your party (P.Abrahams, 17).

5. She quarrels with everybody. No one has a good word for her except old Mad Sam (P.Abrahams, 44).

6. ...I leave to my niece Irene Forsyte, born Irene Heron, by which name she now goes, fifteen thousand pounds free of legacy duty (The Forsyte Saga, 347).

7. Lord Henry Wotton could just catch the gleam of the honey-sweet and honey-coloured blossoms of a laburnum... (O.Wilde, 7).

8. Soames was not so much afraid of them as of his cousin Irene (To Let, 23).

9. It was reckless of me, but I asked Lady Brandon to introduce me to him (O.Wilde, 13).

10. The Jew manager, who was standing at the back of the dress-cicrle, stamped and swore with rage (O.Wilde, 85).

As it is seen from the examples, undetached appositions mainly precede the nouns which they explain. Besides they may follow the noun to which they belong (see sentences 2 and 10). These appositions are the words possessing different shades of meanings. Together with the noun, they belong to, they form one sense group and are pronounced under one stress.

G.Leech and J.Svartvik note that the existing difference between the detached and undetached appositions is like the difference existing between the detached and undetached attributive subordinate clauses (Leech \& Svartvik, 1983)

-Which Mr. Brown do you mean?

-Mr. Brown the doctor or Mr Brown the teacher?

In the given sentences the nouns the doctor and the teacher act as undetached appositions.

Let's consider another example:

I want to speak to Mr. Borwn, the doctor.

As we see from the example in written form the detached apposition is separated from the belonging to the noun with a comma but in the oral pronunciation it being separated from the noun with a pause characterizes it.

The analysis of observations and language facts show that undetached appositions are widely used in the formulation of artistic texts.

It is necessary to note that another group of undetached appositions contains the word combinations with the conjunction "of": the city of London, the prince of Wales, the Duke of Edinburgh, the Straits of Dover, etc.

1. ...Timothy's was but one of the hundreds of such homes in this City of London - the homes of neutral persons of the secure classes (The Forsyte Saga, 148).

2. The King of Ceilan rode through his city with a large ruby in his hand, as the ceremony of his coronation (O.Wilde, 134).

Here arises such a logical question. What kind of link exists between the undetached apposition and the word which it modifies. View points of the scholars dealing with this problem differ as well. These views can be separated into three groups:

1) As to some scholars in the type of word combinations such as the river Volga the leading component is the first word (Ganshina, 1964)

2) As to another group of scholars in the combinations of such type the second side acts as a leading component (Sviblova, 1962)

From the both mentioned thoughts it becomes obvious that undetached appositions are formulated on the principle of subordination.

3) Showing his attitude to this problem prof. L.S.Barkhudarov opposing the both group of scholars mentions that word combinations formulated on the basis of coordination without conjunctions can be divided into two groups: a) copulative word combinations; b) appositive asyndetic phrases.

L.S.Barkhudarov grounding on the view point of O.Jespersen comes to the conclusion that the components of appositive asyndetic phrases are formulated on the ground of coordination (Barkhudarov, 1976). The separately-taken components of such combinations can substitute the whole combination. 
For example:

Tom the lawyer went there.

-Tom went there.

-The lawyer went there.

Let's consider another example.

Aunt Sona visited him.

-Aunt visited him.

-Sona visited him.

See another example.

You my friends saw it.

-You saw it.

-My friends saw it.

We come across the same position in the combinations of Professor Imanov, Colonel Ibadov type. As to .S.Barkhudarov in such combinations only definite article is added (Barkhudarov, 1976).

Imanov came.

The professor came.

I saw colonel Ibadov.

I saw the colonel.

I saw Ibadov.

We meet the same picture in the combinations as the city of London, for example:

I live in the city.

I live in London.

Or

London is the city.

The city is London.

Speaking on the undetached appositions, one more point draws our attention. It is known that in the modern English language there are too many nominal combinations with the preposition "of". Besides that the number of the nominal word combinations on the ground of adjoining is not few.

From this point of view the comparison carried out by B.S.Khaimovich and B.I.Rogovskaya is purposeful and causes our interest. They mention that in the combination of woman doctor type the noun woman acts as the apposition of the noun doctor. This word combination can be transformed as follows:

\section{A doctor (that is a) woman - a woman doctor.}

But in the combination of child psychology it is impossible to carry out transformation in the way as it is mentioned above: psychology (that is a) child (Khaimovich, Rogovskaya, 1967).

From the above mentioned we can come to the conclusion that each component of undetached apposition establishes the following combinations.

Noun + reflexive pronoun

Personal pronoun + all attributive pronoun

Personal pronoun + both attributive pronouns

Personal pronoun + noun

First of all we must mention that taken generally, pronouns are not widely used as undetached appositions. From these viewpoint reflexive pronouns draw our attention much more. Even such an opinion has been formulated that traditionally pronouns which are called group of reflexive pronouns are introduced in two semi-groups: a) reflexive pronouns; b) emphatic pronouns. These authors note that the emphatic pronouns in the stressed position 
are used as emphatic pronouns but the same pronouns in the unstressed position act as reflexive pronouns (Gordon \& Krylova, 1980).

It is worth mentioning that this pointed out opinion does not reflect the reality. Y.G.Birenbaum correctly noted that in no dictionary these words are indicated twice. Consequently he comes to the conclusion that reflexive pronouns carry out two functions: reflexive meaning and the meaning of emphasis (Birenbaum, 1983). These pronouns while carrying out the function of reflexive pronouns act in different syntactic functions, but when they are used in the function of emphasis they act in the function of undetached apposition. For example,

1. He steeped of the track, dumped his cases on the ground, and stretched himself full length on the grass. (P.Abrahams, 27).

2. He told himself to snap out of it but it grew worse (P.Abrahams, 116).

3. "If only you had settled down to some position, and attempted to make something of yourself", she wrote (J.London, 302).

4. They liked him for himself (J.London, 320).

5....He kept repeating to himself (The Forsyte Saga, 183).

As it is seen from the examples reflexive pronouns, can be used as direct, indirect, prepositional and non-prepositional objects.

Now let's pay attention to the cases in which reflexive pronouns can be used as undetached apposition.

1. He himself could not help wondering at the calm of his demeanour, and for a moment felt keenly the terrible pleasure of a double (O.Wilde, 171).

2. I myself would say that it had merely been detected (O.Wilde, 42).

3. They themselves were longing to ask Soames how Irene would take the result, yet knew that they must not; he would perhaps say something of his own accord... (The Forsyte Saga, 286).

As it is seen from the examples, in most cases reflexive pronouns as undetached apposition refers to the subject. At the same time these pronouns can also act as the apposition of other sentence members. It is worth mentioning as it is in other cases, here too we may omit the pronoun, acting in the function of apposition, without damaging the meaning of the sentence. But these pronouns, when being used as concrete sentence members, with the exception of a number of verbs, are impossible to be omitted.

$$
\begin{aligned}
& \text { He washed himself - He washed } \\
& \text { He shaved himself - He shaved } \\
& \text { He dressed himself-He dressed }
\end{aligned}
$$

For example, in the sentence "He blamed himself" if we omit the pronoun himself then the meaning of the sentence will be ununderstandable. But the reflexive pronoun, which is used as an apposition can be easily omitted without damaging the meaning.

\section{He himself could not help wondering - He could not help wondering.}

Besides, we think the omission of this pronoun grammatically to be possible. From the view of general modality of the sentence, serious differences between these two sentences show themselves. Taken as a whole, the both types of modality give special shade of meaning to the general contents of the sentence.

Attributive pronoun all too acts as an undetached apposition. At this time two positions in its usage show themselves.

Pronoun all directly follows the subject, namely it acts as the apposition of the subject.

Let's consider the language facts:

1. The reason we all like to think so well of others is that we are all afraid for ourselves (O.Wilde, 76).

2. We all make mistakes. Don't worry. You really mustn't worry. Everything will be all right (P.Abrahams, 277).

We come across the usage of the pronoun both in the same position. The pronoun both can follow both the subject and the verb. For example:

1. He was eleven, and Cheese-Face was thirteen, and they both carried the Enquirer (J.London, 124).

2. We are both children together (J.London, 166). 
3. In fact, you are both suffering from the disease you think you find in me (J.London, 288).

4. "Undoubtedly you are both excellent doctors", he said (J.London, 288).

5 ....we should both be happy because it was discovered not too late... J.London, 302).

6. They were both beggars. This gave him a strange satisfaction (The Forsyte Saga, 238).

7. "How serious you both are" she cried (O.Wilde, 67).

8. Life has been hard for us both, terribly hard and difficult (O.Wilde, 70).

As it is seen from above-mentioned examples the attributive pronouns all and both as undetached apposition are used after the words they belong to or after the verb. S.Barkhudarov considers that in both cases these pronouns act as subject (Barkhudarov, 1966).

At the same time common nouns together with proper nouns too are used as undetached apposition. For example:

1. You know we poor artists have to show ourselves in society from time to time, just to remind the public that we are not savages (O. Wilde, 12$)$.

2. But you slaves - it is too bad to be slaves, I grant - but you slaves dream of a society (J. London, 295).

3. "You young duffer! Vospovitch is an innovator" (To Let, 15).

4. June looked back at him. "Oh! You Forsyte!" she said, and moved on (To Let, 19).

In a number of cases undetached appositions can also be expressed by numeral as well. For example,

1. "Let's see you dance, you two!" Old Jolyon said (The Forsyte Saga, 344).

2. "What are you two thinking about?" said Lord Henry, strolling over to the table, and putting his cap down (O.Wilde, 188).

\section{Conclusion}

The analysis of the language facts indicated above shows that, apposition and the word which it belongs to, can refer to different parts of speech. In our research we take this principle as a basis. In linguistics there exists such a thought that apposition and the noun which it belongs to, must refer to the same part of speech (Hanan Khatab Omer). Undetached appositions possess vast possibilities of expressing thoughts.

We come to the conclusion that the link between undetached apposition and the noun to which it refers is the link of coordination, in other words it is in the appositive relation. We mention the fact that in teaching English grammar we take practical advantage of detached and undetached appositions.

\section{Reference}

Abrahams, P. (1971). The Path of Thunder.

Barkhudarov, L. S. (1966). Structure of simple sentences in Modern English.

Birenbaum, Y. G. (1983). English reflexive and reinforcing pronouns. Foreign languages at school, 5.

Dolores, M., \& Penas, G. (1994). Apposition in English: A Linguistic Study Based on Literary Corpus. Revista Alicantina de Estudios Ingleses, 7.

Galsworthy, J. (1974). The Forsyte Saga. Book 1.

Galsworthy, J. (1975). To Let. Book 3.

Ganshina, M. A., \& Vasilevskaya, N. M. (1964). English grammar. Moscow.

Gayibova, R. (1958). English Grammar (brief information), Baku.

Gordon, E. M., \& Krylova, I. P. (1980). A grammar of Present-day English (Parts of Speech). Moscow.

Ilyish, B. (1971). The Structure of Modern English. Leningrad.

Khaimovitch, B. S., \& Rogovskaya, B. I. (1967). A course in English Grammar. Moscow.

Kobrina, N. A., \& Korneeva, E. A. (1965). An outline of ME Syntax. Moscow

Leech, G., \& Svartvik, J. (1983). A Communicative Grammar of English. Moscow.

London J. (1980). Martin Eden. Kiev.

Omer, H. K. (n.d.). Apposition in English. Tirkit University Journal for Humanities, 18(8). 
Quirk, R. (1982). A university grammar of English.

Sviblova, T. A. (1962). The question of restricting the separate determination of similar grammatical structures. Philology, 1.

Turksever (Musayev), O. (2007). English Grammar. Baku.

Van Yuy-fu. (1959). Some controversial issues of studying isolated minor sentence. Russian at school, 1.

Wilde, O. (1978). The Picture of Dorion Gray. Kiev.

\section{Copyrights}

Copyright for this article is retained by the author(s), with first publication rights granted to the journal.

This is an open-access article distributed under the terms and conditions of the Creative Commons Attribution license (http://creativecommons.org/licenses/by/3.0/). 